\title{
The Research of Alkaline Release Characteristics of Biological Adaptive Porous Concrete
}

\author{
Liguang XIAO ${ }^{1, a}$, Dawei JIANG ${ }^{1, b}$
}

${ }^{1}$ School of Materials Science and Engineering, Jilin Jianzhu university, Changchun 130118, China

axlg627@163.com, b775008831@qq.com

\begin{abstract}
Keywords: Porous concrete; Alkaline; Change rule; Features
Abstract. In this article, the acid-base properties of porous concrete leaching solution were studied, The $\mathrm{pH}$ value of the porous concrete soaking solution was measured by the method of continuous soaking and repeated soaking, at the same time, the $\mathrm{pH}$ value of leaching solution and the ex-situ leaching method were compared and analyzed. The results show that the alkaline release are significant differences between porous concrete and conventional concrete. In the unit time, the alkaline release rate of porous concrete is faster than the rate of ordinary concrete. Moreover, the $\mathrm{pH}$ value of the leaching solution is significantly decreased after soaking several times, and it is also shown that there is a positive correlation between the rate of alkali release and porosity of porous concrete. At the same time, it is concluded that the ex-situ leaching method is not suitable for the alkaline practical measurement of the porous concrete.
\end{abstract}

\section{Introduction}

With the development and application of the new concept of architecture, the design of the sponge city gradually appeared in people's life ${ }^{[1-2]}$. And more and more researchers are also attracted by the green concrete, vegetation and biological adaptive concrete. However, the study on the alkaline release characteristics of the porous concrete has not been paid much attention, and the ex-situ leaching method is a preferred method used to evaluate the alkalinity of the porous concrete ${ }^{[3]}$, Although this method has a more mature application effect. However, the specific surface area and pore characteristics of porous concrete are different from those of conventional concrete,Therefore, there is great differences of alkaline release characteristics between porous concrete and conventional concrete. we have studied the alkali release relationship between porous concrete of different particle size and the original concrete.

\section{The Materials and Test Methods}

2.1 The main raw material and testing equipment. (1) Cement: adopt the cement of ordinary Portland cement, and it has the strength grade of 42.5 .

(2) Aggregate: aggregate is selected according to the standard of sand for ordinary concrete, the characteristics of coarse aggregate are shown in Table 1, the fine aggregate is the medium sand of fineness modulus with 2.6, and the $\mathrm{PH}$ of coarse aggregate filtrate is neutral.

(3) Water: distilled water (PH6.8-7.0).

(4) PH measuring instrument: Leici PHS-25 PH measuring instrument product by Shanghai Shengke equipment limited company.

Tab.1. Characteristics of coarse aggregate

\begin{tabular}{llll}
\hline Aggregate number & G1 & G2 & G3 \\
\hline Particle size $(\mathrm{mm})$ & $10-20$ & $5-10$ & 5 \\
\hline
\end{tabular}

2.2 Test Method. (1) the test piece size is $100 * 100 * 100 \mathrm{~mm}$, specimen making:This experiment uses $\mathrm{W} / \mathrm{C}=0.3$, the experimental group and the mix proportion arrangement as shown in table 2 . The experimental group A1-A5 was the standard experimental group, A1-A3 was porous concrete, A4 was no aggregate cement paste test block, A5 was solid mortar test block; A6 was the blank test group, and the component was distilled water. 
Tab.2. Proportion of block production

\begin{tabular}{lllll}
\hline block number & Aggregate number & Aggregate $(\mathrm{g})$ & Water(g) & Cement $(\mathrm{g})$ \\
\hline A1 & G1 & 1600 & 120 & 400 \\
A2 & G2 & 1600 & 120 & 400 \\
A3 & G3 & 1600 & 120 & 400 \\
A4 & - & - & 120 & 400 \\
A5 & sand & 1600 & 120 & 400 \\
A6 & - & - & - & - \\
\hline
\end{tabular}

Block A1, A2, A3 and A5 were cube with the side of $100 \mathrm{~mm}$. Block A4 was a cube with $100 * 100 \mathrm{~mm}$ bottom edge length and $31.12 \mathrm{~mm}$ hight length.

(2) Test measurement: This experiment adopts the method of Porosity measurement from "porosity test program" and "river water permeable concrete construction manual" ${ }^{[4]}$.Computation formula is as follows.

$$
\mathrm{P}=\left(1-\left(\mathrm{W}_{2}-\mathrm{W}_{1}\right)\right) / 100
$$

P-connectivity rate $(\%) ; \mathrm{W}_{2}$-the weight of the test block take out of water after $24 \mathrm{~h}(\mathrm{~g})$; $\mathrm{W}_{1}$-the weight of the test block in water after $24 \mathrm{~h}(\mathrm{~g})$; V-specimen appearance volume $\left(\mathrm{cm}^{3}\right)$.

The ex-situ leaching method: selected sample crushing, grinding, sieving $(0.08 \mathrm{~mm})$, take samples with $10 \mathrm{~g}$, added the samples to 10 times weight distilled water, in order to prevent the carbide plugged the bottle, shake evenly every $5 \mathrm{~min}$, determination the $\mathrm{pH}$ value after filtered by filter in $2 h$.

Method for measuring the leaching solution: put the test block in the $1000 \mathrm{ml}$ beaker, and add $500 \mathrm{ml}$ distilled water

\section{The Test Results and Discussion}

3.1 Block Porosity Measurements. The A1, A2 and A3 were measured according to the method of connected porosity, and the measured results are shown in table 3. Compared with the measured results, we can get the porosity of connected hole A2>A1>A3.

Tab.3. Hole porosity test results

\begin{tabular}{lllll}
\hline Block number & $\mathrm{W}_{2}(\mathrm{~g})$ & $\mathrm{W}_{1}(\mathrm{~g})$ & $\mathrm{V}\left(\mathrm{cm}^{3}\right)$ & $\mathrm{P}(\%)$ \\
\hline $\mathrm{A} 1$ & 1857.4 & 1030.6 & 1000 & 17.30 \\
$\mathrm{~A} 2$ & 1843.6 & 1053.8 & 1000 & 21.05 \\
$\mathrm{~A} 3$ & 1840.7 & 990.1 & 1000 & 14.96 \\
\hline
\end{tabular}

3.1.1 Analysis on the Change of $\mathbf{P H}$ in Long Term Immersion.A1-A6 continuous measurement $\mathrm{pH}$ results as shown in Table 4, A1-A6 pH change rule as shown in Figure 1, A1-A3 $\mathrm{pH}$ contrast as shown in figure 2 .

In the 10min-6h measurement period, A1-A3 test alkaline release amount was significantly higher than the of A5 and A4 in a unit of time, In the 10min- $2 \mathrm{~h}$ measurement time period, the basic release rate of A4 is greater than A5, the basic release rate of A5 is more than A4 after $2 \mathrm{~h}$, and it can be found that the alkali release rate of porous concrete is $\mathrm{A} 2>\mathrm{A} 1>\mathrm{A} 3$.

Tab.4. Continuous measurement $\mathrm{pH}$ results

\begin{tabular}{lllllll}
\hline measuring time & A1 & A2 & A3 & A4 & A5 & A6 \\
\hline 10min & 9.07 & 9.25 & 9.15 & 7.66 & 7.61 & 6.98 \\
20min & 9.49 & 9.30 & 9.33 & 7.83 & 7.69 & 6.98 \\
30min & 9.30 & 9.55 & 9.29 & 8.00 & 7.74 & 6.99 \\
40min & 9.46 & 9.55 & 9.33 & 8.90 & 8.13 & 6.97 \\
50min & 9.61 & 9.57 & 9.53 & 9.08 & 8.67 & 6.97 \\
60min & 9.64 & 9.78 & 9.92 & 9.25 & 8.75 & 6.97 \\
2h & 10.42 & 11.08 & 10.79 & 9.80 & 9.93 & 6.98 \\
3h & 11.54 & 11.92 & 11.43 & 9.82 & 9.99 & 7.00 \\
4h & 11.80 & 12.20 & 11.90 & 10.05 & 10.52 & 6.99 \\
5h & 12.14 & 12.23 & 12.42 & 10.62 & 11.00 & 6.89 \\
6h & 12.26 & 12.28 & 12.23 & 10.83 & 11.08 & 6.91 \\
\hline
\end{tabular}




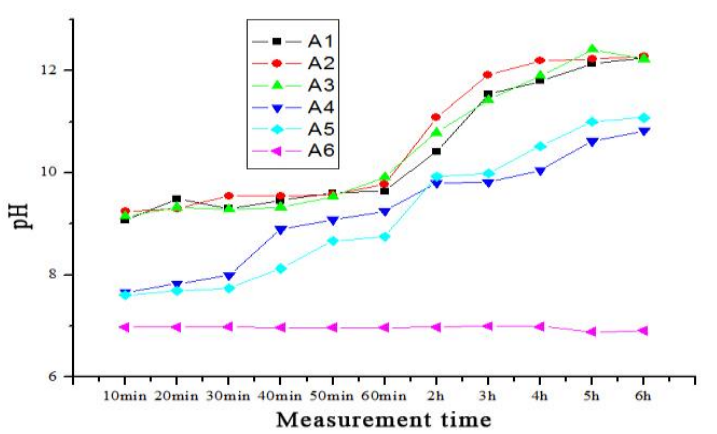

Fig.1. A1-A6 pH change rule

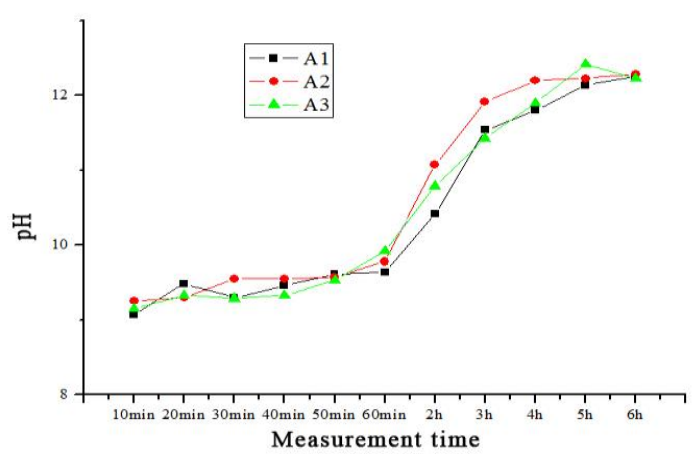

Fig.2. A1-A3 pH contrast

through the above analysis and comparison of A1, A2, A3, can be found that there is a positive correlation of alkaline release rate with porosity of porous concrete, the alkaline release rate increased with the porous increased of porous concrete. Through the comparative analysis of A4 and A5, it can be found that under the condition of the same amount of cement, with the increase of immersion time, the surface area will determine the alkalinity release amount of concrete in unit time.

3.1.2 PH Analysis of Many Times Water Changed. The change of $\mathrm{pH}$ value of interval water exchange is shown in Table 5. $\mathrm{PH}$ of water exchange with $2 \mathrm{~h}$ is shown in figure 3 , $\mathrm{PH}$ of water exchange with $1 \mathrm{~h}$ is shown in figure 4.

Tab.5. The change of $\mathrm{pH}$ value of interval water exchange

\begin{tabular}{lllllll}
\hline \multirow{2}{*}{ Block number } & \multicolumn{6}{l}{ Water changing times } \\
\cline { 2 - 7 } & 1 & 2 & 3 & 4 & 5 & 6 \\
\hline A1 & 10.02 & 9.84 & 9.74 & 9.23 & 9.21 & 9.06 \\
A2 & 9.80 & 9.80 & 9.57 & 9.51 & 9.05 & 9.04 \\
A3 & 10.70 & 9.89 & 9.61 & 9.50 & 9.25 & 9.09 \\
A4 & 9.41 & 9.43 & 9.49 & 8.60 & 8.71 & 8.80 \\
A5 & 9.51 & 9.62 & 9.42 & 8.85 & 8.84 & 9.01 \\
A6 & 6.98 & 6.99 & 6.98 & 6.98 & 6.95 & 6.98 \\
\hline
\end{tabular}

It can be found that the $\mathrm{pH}$ of $\mathrm{A} 1-\mathrm{A} 3$ test of porous concrete showed a downward trend after several times of water change, but the $\mathrm{pH}$ change of A4, A5 solution is very small, and instead of a certainly increase.

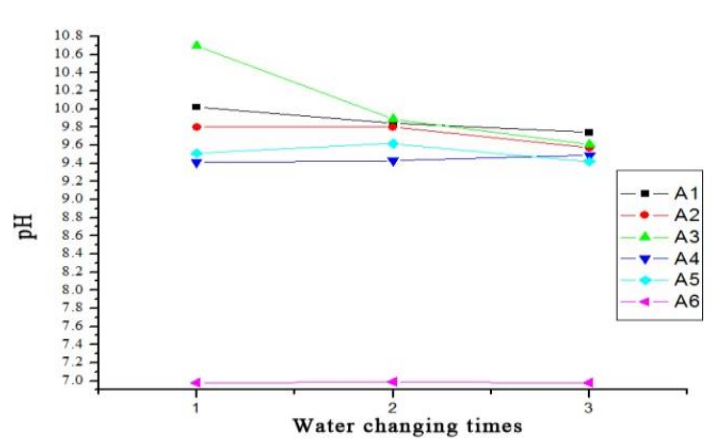

Fig.3. $\mathrm{pH}$ of water exchange with $2 \mathrm{~h}$

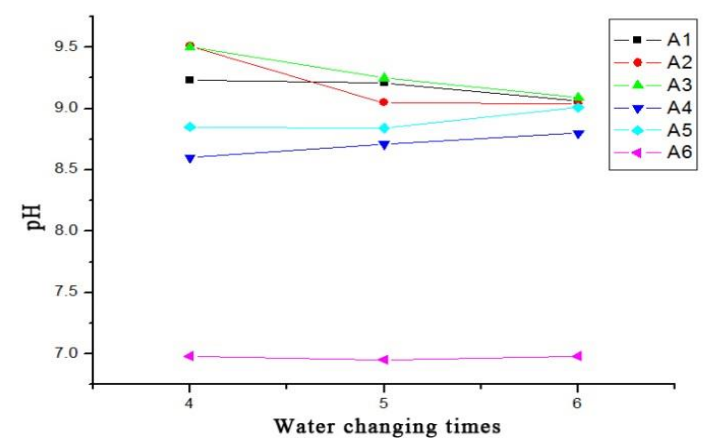

Fig.4. $\mathrm{pH}$ of water exchange with $1 \mathrm{~h}$ The Ex-situ Leaching Method. pH with ex-situ leaching as shown in table 6.

Tab.6. $\mathrm{pH}$ with ex-situ leaching

\begin{tabular}{llllll}
\hline Block number & A1 & A2 & A3 & A4 & A5 \\
\hline $\mathrm{pH}$ & 12.55 & 12.45 & 12.51 & 12.70 & 12.67 \\
\hline
\end{tabular}

It can be found that the $\mathrm{pH}$ value of A1-A5 is basically consistent. The results are different from the measurement result of immersion method, and it can be found is very difficult to make sample of ex-situ leaching method (as shown in Figure 6), Therefore, the solid liquid extraction method is very effective for the measurement of the alkaline release characteristics of the porous concrete. 


\section{Conclusion}

The results show that there is obvious difference of alkaline release characteristics between the porous concrete and the traditional concrete. At first, the basic alkaline release rate of porous concrete was significantly higher than the ordinary concrete in unit time. And the $\mathrm{pH}$ of porous concrete leaching decreased significantly after several times of soaking treatment. And according to the comparative analysis of the porosity and the alkaline solution of A1, A2, A3, it can be found that there is a positive correlation between the rate of alkali release and porosity of porous concrete, and the solid liquid extraction method is very effective for the measurement of the alkaline release characteristics of the porous concrete. For porous and adaptable concrete, in particular, the biological adaptation of water coagulation, more practical methods should be explored.

\section{Acknowledgments}

This work was financially supported by the National Key Technologies Research and Development Program of China (No. 2016YFC0701002).

\section{References}

[1] Xudong Ding, Hongxing Yang,Chengguang Zhao,Shengli Wang. The research and application of green concrete [J]. New Building Materials. 2015 (5) p.30-32.

[2] Gui-ling Wang, Long-zhi Wang, Hai-xia Zhang, Xin Cui, Shenghui Song. Meaning,technology index and research emphases of planting eco- concrete[J]. Concrete.2013(1) p.105-113.

[3] C .J .Newton, J .M.Sykes, The Effect of Salt Additions on the Alkalinity of $\mathrm{Ca}(\mathrm{OH})_{2}$ Solutions [J].Cement and Concrete Resarch.1987(17) p.765-776.

[4] Yanlian Xu, Rongwei Li, Qi-un Yu, WEI Jiang-xiong Wei, Li-ying Wei, Xue-jun Tan, Ping Xiao. Pore representation and the relationship between pore and permeability of the porous concrete[J]. Concrete.2009(3) p.16-20. 